University of Wollongong

Research Online

Faculty of Engineering and Information

Faculty of Engineering and Information

Sciences - Papers: Part A

Sciences

$1-1-2015$

Brittle versus ductile fracture behaviour in nanotwinned FCC crystals

Linqing Pei

University of Wollongong, Ip115@uowmail.edu.au

Cheng Lu

University of Wollongong, chenglu@uow.edu.au

A Kiet Tieu

University of Wollongong, ktieu@uow.edu.au

Xing Zhao

University of Wollongong, xz920@uowmail.edu.au

Liang Zhang

University of Wollongong, Iz592@uowmail.edu.au

See next page for additional authors

Follow this and additional works at: https://ro.uow.edu.au/eispapers

Part of the Engineering Commons, and the Science and Technology Studies Commons

Research Online is the open access institutional repository for the University of Wollongong. For further information contact the UOW Library: research-pubs@uow.edu.au 


\title{
Brittle versus ductile fracture behaviour in nanotwinned FCC crystals
}

\author{
Abstract \\ Molecular dynamic simulation (MD) was used to study the brittle versus ductile fracture behaviour in \\ nanotwinned Face Centred Cubic (FCC) crystals subjected to the uniaxial tensile deformation. A \\ fundamental brittle versus ductile fracture is observed, which can be mainly understood in terms of the \\ ratio of surface energy to unstable stacking fault energy or the ratio of ideal tensile strength to ideal shear \\ strength in atomic model with a confined range of twinning spacing. Results show that the small ratio \\ value is favourable for the brittle fracture, and vice versa, the big one supports the ductile fracture. \\ Disciplines \\ Engineering | Science and Technology Studies \\ Publication Details \\ Pei, L., Lu, C., Tieu, K., Zhao, X., Zhang, L., Cheng, K. \& Michal, G. (2015). Brittle versus ductile fracture \\ behaviour in nanotwinned FCC crystals. Materials Letters, 152 65-67. \\ Authors \\ Linqing Pei, Cheng Lu, A Kiet Tieu, Xing Zhao, Liang Zhang, Kuiyu Cheng, and Guillaume Michal
}




\title{
Brittle versus ductile fracture behaviour in nanotwinned FCC crystals
}

Linqing Pei, Cheng Lu*, Kiet Tieu, Xing Zhao, Liang Zhang, Kuiyu Cheng, Guillaume Michal

School of Mechanical, Materials and Mechatronic Engineering, University of Wollongong, Wollongong, NSW 2522, Australia

*Corresponding author. Tel.:+6142214639; fax: +61242213101; E-mail address:

chenglu@uow.edu.au (C. Lu)

\begin{abstract}
Molecular dynamic simulation (MD) was used to study the brittle versus ductile fracture behaviour in nanotwinned Face Centred Cubic (FCC) crystals subjected to the uniaxial tensile deformation. A fundamental brittle versus ductile fracture is observed, which can be mainly understood in terms of the ratio of surface energy to unstable stacking fault energy or the ratio of ideal tensile strength to ideal shear strength in atomic model with a confined range of twinning spacing. Results show that the small ratio value is favourable for the brittle fracture, and vice versa, the big one supports the ductile fracture.
\end{abstract}

Keywords: Molecular dynamics; Nanotwinned crystal; Fracture

\section{Introduction}

The issue of brittle versus ductile response of solid has attracted much attention. Griffith [1] proposed a criterion that crack grew as the energy release rate must be larger than the energy required for creation of new surfaces. Kelly et al. [2] went further the perspective of brittle versus ductile response that a solid would be either inherently 
ductile or inherently brittle, mainly depending on the ratio between the theoretical shear strength and the theoretical tensile strength. Rice and Thomson [3] believed that a correct description of this brittle versus ductile behaviour should be involved the competition of cleavage and dislocation emission. The brittle versus ductile transition could be simply characterized by the ratio between unstable stacking fault $\left(r_{u s f}\right)$ and free surface energy $\left(r_{\text {sur }}\right)$ [4]. In contrast, Zhou [5] argued that the brittle-to-ductile crossover of crack was independent on the surface energy, but only related to the unstable stacking fault.

Nanotwinned metals exhibits an unusual combination of ultra-high yield strength and high ductility. Zhu, et al. [6, 7] discovered that the existing of twin boundary (TB) was able to increase both the strength and ductility in metals. However, the TB was regarded as one kind of intrinsically brittle grain boundaries [8]. Interestingly, Li and Wang [9, 10] have recently shown the totally opposite conclusions that the brittle-to-ductile fracture can be occurred when the TB spacing changes beyond a critical value.

Just as above mentioned, previous experimental and MD simulation results exhibit similar or even contradictory comparing with the classic continuum theory. It poses an interesting question: whether the continuum concept of free surface energy versus unstable stacking fault energy, or ideal shear strength versus ideal tensile strength can be used to predict the brittle/ductile fracture in nanotwinned FCC crystals by MD simulation? In this study, MD simulations were performed to explore this question.

\section{Molecular dynamics simulation model}

Geometric size of each atomic model of FCC crystals is kept about $86 \times 80 \times 5$ lattices in $X, Y$ and $Z$ directions. The crack plane lies on the $(\overline{1} 1 \overline{1})_{M}$ plane, the crack 
propagation direction runs along $[1 \overline{1} \overline{2}]_{M} /[1 \overline{1} \overline{2}]_{T}$ (X direction), and the crack front direction along $[110]_{M} /[\overline{1} \overline{1} 0]_{T}$ orientation $(Z$ direction). TBs with spacing of 20 atom layers were introduced into the FCC single crystals along $[\overline{1} 1 \overline{1}]_{M} /[1 \overline{1} 1]_{T}$ direction $(Y$ direction). Here, the subscript $M$ and $T$ means matrix crystal and twinned crystal, respectively. An initially left-hand notched crack was inserted into the sample. In order to create a local region for stress concentration, one of the crack planes was aligned with the TB plane. Periodical boundary conditions were imposed along the crack front direction and tension direction. The Embedded atom method (EAM) interatomic potentials were adopted. All simulations were performed using a Nose-Hoover thermostat and a Parinello-Rahman barostat [11]. A time algorithm was used with a time step of 3 femtoseconds. Before tensile deformation, each model was relaxed for $300 \mathrm{ps}$ at $1.1 \mathrm{~K}$ and 0 bar external stress. Then a constant strain rate of $1 \times 10^{8} \mathrm{~s}^{-1}$ was applied along $\mathrm{Y}$ axis at $1.1 \mathrm{~K}$ until it stretched to $10 \%$ deformation.

\section{Results and discussion}

We carried out MD simulations using EAM potential to calculate the stacking fault energies and surface energies of FCC metals. Each case was conducted a full minimization to ensure the accuracy of those parameters. Table 1 shows the calculated results which are in good agreement with Li and Deng, et al. [9, 12-15]. It is observed that for different FCC metals, the energetic parameters exhibit big differences. That will result in an obvious distinction in fracture behavior of metals. To evaluate the competition between crack cleavage and dislocation emission around the crack tip, it was calculated the ratio of $\left(2 r_{s u r}-r_{t b}\right) / r_{u s f}$, where $r_{t b}$ is the TB energy. Because of the small value of TB energy, the equation can be approximately simplified to 
$2 r_{\text {sur }} / r_{u s f}$. According to the brittle versus ductile fracture mechanism in continuum theory, the small ratio value represents a preferential brittle fracture. Therefore, it can be predicted that the twinned $\mathrm{Al}, \mathrm{Ni}, \mathrm{Ag}, \mathrm{Cu}$ metals exhibit more brittleness in comparison with the $\mathrm{Au}, \mathrm{Pb}, \mathrm{Pd}, \mathrm{Pt}$ metals during the crack propagation.

Table 1. Calculated energetic parameters by MD simulation for various FCC metals.

\begin{tabular}{cccccc}
\hline Metal & $\begin{array}{c}\boldsymbol{r}_{\boldsymbol{u s f}} \\
\left(\boldsymbol{m} \boldsymbol{J} / \boldsymbol{m}^{\mathbf{2}}\right)\end{array}$ & $\begin{array}{c}\boldsymbol{r}_{\boldsymbol{s u r}} \\
\left(\boldsymbol{m} \boldsymbol{J} / \boldsymbol{m}^{\mathbf{2}}\right)\end{array}$ & $\begin{array}{c}\boldsymbol{r}_{\boldsymbol{t} \boldsymbol{b}} \\
\left(\boldsymbol{m} \boldsymbol{J} / \boldsymbol{m}^{2}\right)\end{array}$ & $\frac{\left(2 \boldsymbol{r}_{\boldsymbol{s u r}}-\boldsymbol{r}_{\boldsymbol{t} \boldsymbol{b}}\right)}{\boldsymbol{r}_{\boldsymbol{u s f}}}$ & $\begin{array}{c}\text { Crack } \\
\text { mode }\end{array}$ \\
\hline $\mathbf{A l}$ & 218.77 & 428 & 64.91 & 3.25 & Brittle \\
$\mathbf{N i}$ & 379.21 & 1284 & 98.28 & 6.77 & Brittle \\
$\mathbf{A g}$ & 114.59 & 862 & 9.16 & 14.97 & Brittle \\
$\mathbf{C u}$ & 161.31 & 1239 & 22.24 & 15.22 & Brittle \\
$\mathbf{P d}$ & 135.68 & 1515 & 8.50 & 22.27 & Ductile \\
$\mathbf{P t}$ & 168.71 & 2083 & 38.44 & 24.47 & Ductile \\
$\mathbf{A u}$ & 90.07 & 1193 & 19.88 & 26.47 & Ductile \\
$\mathbf{P b}$ & 23.94 & 348 & 1.79 & 29.00 & Ductile \\
\hline
\end{tabular}

Fig. 1 shows the tensile stress-strain curves for varying nanotwinned FCC metals under unaixal tensile deformation. By combining with the ratio of surface energy to unstable stacking fault listed in Table 1, it can be seen the striking brittle versus ductile fracture by identifying that the stress drops sharply to near zero GPa (corresponding to small ratio value) or stress decreases slowly to low level (corresponding to big ratio value) after the stress reaches the peak value. A small value $\left(2 r_{s u r} / r_{u s f}\right)$ exhibits a brittle fracture, whereas the big value is preferred a ductile fracture, same with the prediction in continuum theory [4]. In other words, for a small value of materials like Al, $\mathrm{Ni}, \mathrm{Cu}, \mathrm{Ag}$, the relatively low surface energy (meaning a low barrier to generate the new surface) and the relatively high unstable stacking fault (meaning a larger energy barrier to atomic sliding on the slip plane) show the brittle fracture behavior. For higher ratio of $2 r_{\text {sur }} / r_{u s f}$ of materials like $\mathrm{Pt}, \mathrm{Pd}, \mathrm{Au}, \mathrm{Pb}$, dislocation activities become easier prior to the initiation of crack cleavage. The fracture shows a completely ductile manner. 


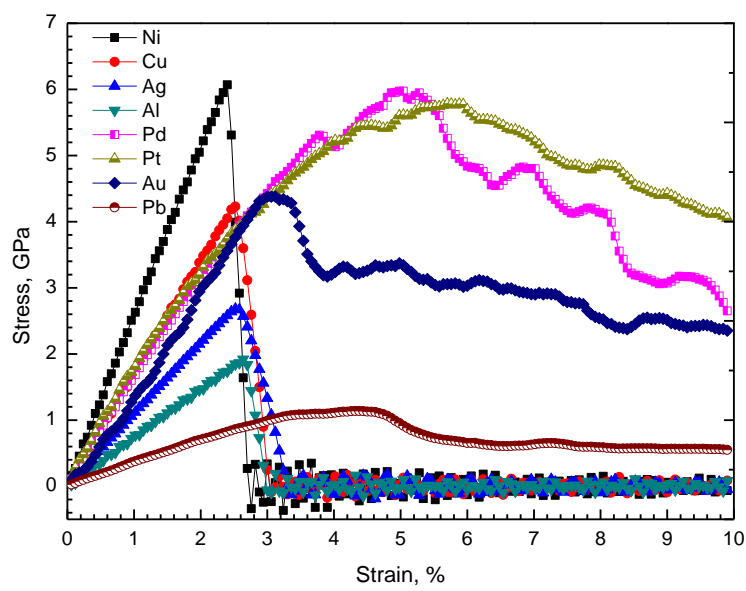

Fig. 1 Tensile stress versus strain for various FCC metals with twinning spacing of 20 atom layers.

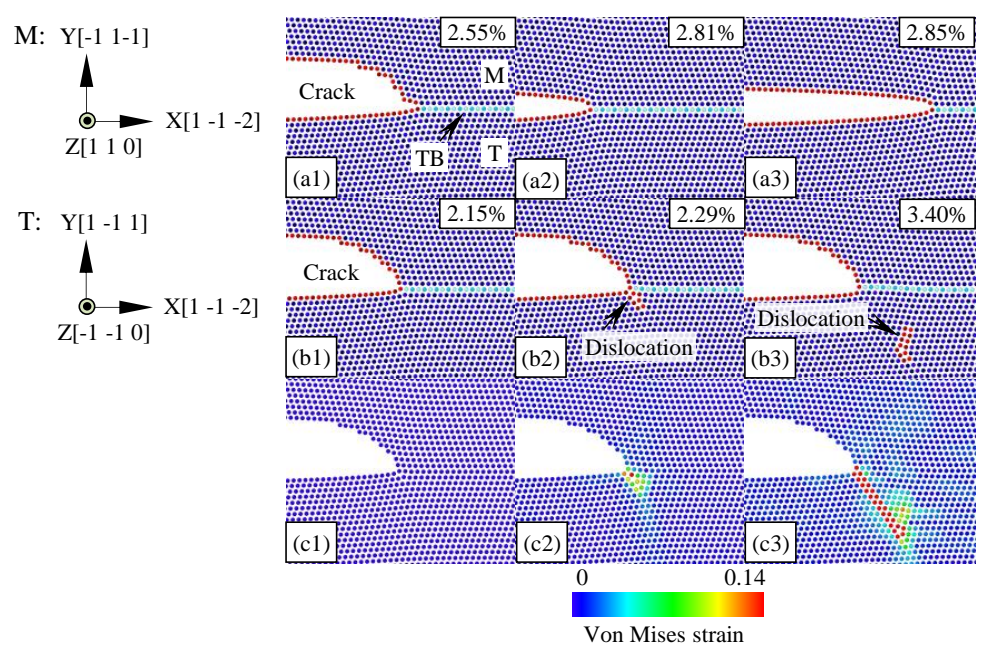

Fig. 2 Atomistic views of crack propagation around the crack tip: (a) Cu; (b-c) Au. Atoms are coloured in (a-b) according to the common neighbour analysis. The light and dark colour of same colour in (a-b) means two successive atom layers in $[110]_{M} /[\overline{1} 10]_{T}$ direction. Atoms in (c) are shown by Von Mises strain.

The detailed crack propagation mechanism around the crack tip can be understood from the atomic configuration. Fig. 2 shows the two obviously distinct fracture behavior for $\mathrm{Cu}$ (brittle) and $\mathrm{Au}$ (ductile). The $\mathrm{Cu}$ with relatively low ductile indicator $\left(2 r_{\text {sur }} / r_{u s f}\right)$ suggests the much strong tensile characteristic competing over the shear effect. Atomic bonding is easy to break rather than the inhomogeneous dislocation 
nucleates from the crack tip. The crack moves forward with flat surfaces without any dislocation activity. In comparison of $\mathrm{Cu}, \mathrm{Au}$ with a high $2 r_{\text {sur }} / r_{u s f}$ owns lower dislocation energy barrier, dislocation-associated mechanism dominates the entire plastic deformation, resulting in a completely ductile fracture failure.

Table 2. Calculated ideal tensile strength and ideal shear strength parameters by MD simulation.

\begin{tabular}{ccccc}
\hline Metal & $\boldsymbol{\sigma}_{\boldsymbol{c}}(\mathbf{G P a})$ & $\boldsymbol{\tau}_{\boldsymbol{c}}(\mathbf{G P a})$ & $\left(\boldsymbol{\sigma}_{\boldsymbol{c}} \cdot \boldsymbol{S}\right) / \boldsymbol{\tau}_{\boldsymbol{c}}$ & Crack mode \\
\hline $\mathbf{A l}$ & 8.79 & 2.76 & 0.516 & Brittle \\
$\mathbf{N i}$ & 24.35 & 11.20 & 0.683 & Brittle \\
$\mathbf{A g}$ & 10.46 & 3.66 & 0.897 & Brittle \\
$\mathbf{C u}$ & 16.84 & 4.88 & 1.085 & Brittle \\
$\mathbf{P d}$ & 17.12 & 4.15 & 1.296 & Ductile \\
$\mathbf{P t}$ & 21.63 & 4.97 & 1.368 & Ductile \\
$\mathbf{A u}$ & 11.62 & 2.58 & 1.416 & Ductile \\
$\mathbf{P b}$ & 3.24 & 0.62 & 1.653 & Ductile \\
\hline
\end{tabular}

Besides that, an alternative criterion was also made to determine the brittle and ductile response by involving the ideal tensile strength $\left(\sigma_{c}\right)$ and the ideal shear strength $\left(\tau_{c}\right)$. The method to calculate the ideal strength can be referred to Ref. [16]. Each parameter was calculated by MD simulation at near $0 \mathrm{~K}$ after enough energy relaxation, as shown in Table. 2. We judged the indicator value of $A=\left(\sigma_{c} \cdot S\right) / \tau_{c}$, where $S$ is the Schmid factor. Generally, $A<1$, the metals tend to be brittle fracture due to the strong shear effect to atom shear on slip plane. Conversely, $A>1$, the metals prefer the ductile fracture behavior. In Table $2 \mathrm{Au}, \mathrm{Pb}, \mathrm{Pd}, \mathrm{Pt}$ all with values of $A$ much larger than 1 , it indicates these metals fail in an obviously ductile fracture behavior. For other FCC metals, it is predicted the brittle fracture. In the case of $\mathrm{Cu}$, although the indicator $A$ is a little slightly larger than 1 , under the aid of the inserted $\mathrm{TBs}$, the $\mathrm{Cu}$ can still be cleavage in a brittle manner. 


\section{Conclusions}

Our results provide an atomic scale view of change of the crack-tip events from the crack cleavage to dislocation activity in twinned FCC crystals under low temperature. The classic theories of ratio of surface energy and unstable stacking fault energy, as well as the ratio of ideal tensile strength and ideal shear strength in determining the brittle versus ductile fracture behavior for nanotwinned FCC crystals can be useful in a specific twinning spacing range. But keeping in a mind, these approaches will lose effectiveness in predicting the brittle and ductile response when the TB spacing is out of the limited range (see the brittle-to-ductile fracture transition in twinned $\mathrm{Cu}$ with various twinning spacings in Ref. [9]). Much care should be also taken to consider other influence factors: temperature, size effect, surface feature, the applied strain rate, etc. which may alter the applicability of the continuum theories.

\section{Acknowledgements}

The authors acknowledge support from the China scholarship council and University of Wollongong in Australia.

\section{References}

[1] Griffith AA. The phenomena of rupture and flow in solids. Philosophical Transactions of the Royal Society of London. 1921;221:163-98.

[2] Kelly A, Tyson WR, Cottrell AH. Ductile and brittle crystals. Philosophical Magazine. 1967;15:56786.

[3] Rice JR, Thomson R. Ductile versus brittle behaviour of crystals. Phil Mag. 1974;29:73-97.

[4] Rice JR. Dislocation nucleation from a crack tip: An analysis based on the Peierls concept. Journal of the Mechanics and Physics of Solids. 1992;40:239-71. 
[5] Zhou SJ, Carlsson AE, Thomson R. Crack blunting effects on dislocation emission from cracks. Physical Review Letters. 1994;72:852-5.

[6] Zhu T, Gao H. Plastic deformation mechanism in nanotwinned metals: An insight from molecular dynamics and mechanistic modeling. Scripta Materialia. 2012;66:843-8.

[7] Lu K, Lu L, Suresh S. Strengthening materials by engineering coherent internal boundaries at the nanoscale. Science. 2009;324:349-52.

[8] Cheng Y, Jin ZH, Zhang YW, Gao H. On intrinsic brittleness and ductility of intergranular fracture along symmetrical tilt grain boundaries in copper. Acta Materialia. 2010;58:2293-9.

[9] Jang D, Li X, Gao H, Greer JR. Deformation mechanisms in nanotwinned metal nanopillars. Nature Nanotechnology. 2012;7:594-601.

[10] Wang J, Sansoz F, Huang J, Liu Y, Sun S, Zhang Z, et al. Near-ideal theoretical strength in gold nanowires containing angstrom scale twins. Nat Commun. 2013;4:1742.

[11] Parrinello M, Rahman A. Polymorphic transitions in single crystals: A new molecular dynamics method. Journal of Applied Physics. 1981;52:7182-90.

[12] Deng C, Sansoz F. Fundamental differences in the plasticity of periodically twinned nanowires in Au, $\mathrm{Ag}, \mathrm{Al}, \mathrm{Cu}, \mathrm{Pb}$ and Ni. Acta Materialia. 2009;57:6090-101.

[13] Jang D, Li X, Gao H, Greer JR. Deformation mechanisms in nanotwinned metal nanopillars. Nat Nano. 2012;advance online publication.

[14] Mendelev MI, Kramer MJ, Becker CA, Asta M. Analysis of semi-empirical interatomic potentials appropriate for simulation of crystalline and liquid $\mathrm{Al}$ and $\mathrm{Cu}$. Philosophical Magazine. 2008;88:1723-50.

[15] Williams PL, Mishin Y, Hamilton JC. An embedded-atom potential for the $\mathrm{Cu}-\mathrm{Ag}$ system. Modelling and Simulation in Materials Science and Engineering. 2006;14:817-33.

[16] Kang K, Cai W. Brittle and ductile fracture of semiconductor nanowires - molecular dynamics simulations. Philosophical Magazine. 2007;87:2169-89. 